\title{
Roles of Microglial Phagocytosis and Inflammatory Mediators in the Pathophysiology of Sleep Disorders
}

\author{
Agnes Nadjar ${ }^{1,2,3}$, Henna-Kaisa M. Wigren ${ }^{4}$ and Marie-Eve Tremblay ${ }^{5,6 *}$ \\ ${ }^{1}$ Nutrition et Neurobiologie Intégrée, UMR 1286, Institut National de la Recherche Agronomique, Bordeaux, France, \\ ${ }^{2}$ Nutrition et Neurobiologie Intégrée, UMR 1286, Bordeaux University, Bordeaux, France, ${ }^{3}$ OptiNutriBrain International \\ Associated Laboratory (NutriNeuro France-INAF Canada), Québec, QC, Canada, ${ }^{4}$ Faculty of Medicine/Medicum, University \\ of Helsinki, Helsinki, Finland, ${ }^{5}$ Axe Neurosciences, CRCHU de Québec-Université Laval, Québec, QC, Canada, \\ ${ }^{6}$ Département de médecine moléculaire, Université Laval, Québec, QC, Canada
}

OPEN ACCESS

Edited by:

Francesco Fornai,

University of Pisa, Italy

Reviewed by:

Alfredo Kirkwood,

Johns Hopkins University,

United States

Alessandro Stefani,

Università degli Studi di Roma Tor

Vergata, Italy

*Correspondence:

Marie-Eve Tremblay

tremblay.marie-eve@

crchudequebec.ulaval.ca

Received: 03 March 2017 Accepted: 07 August 2017 Published: 30 August 2017

Citation:

Nadjar A, Wigren H-KM and Tremblay M-E (2017) Roles of

Microglial Phagocytosis and Inflammatory Mediators in the

Pathophysiology of Sleep Disorders.

Front. Cell. Neurosci. 11:250.

doi: 10.3389/fncel.2017.00250
Sleep serves crucial learning and memory functions in both nervous and immune systems. Microglia are brain immune cells that actively maintain health through their crucial physiological roles exerted across the lifespan, including phagocytosis of cellular debris and orchestration of neuroinflammation. The past decade has witnessed an explosive growth of microglial research. Considering the recent developments in the field of microglia and sleep, we examine their possible impact on various pathological conditions associated with a gain, disruption, or loss of sleep in this focused mini-review. While there are extensive studies of microglial implication in a variety of neuropsychiatric and neurodegenerative diseases, less is known regarding their roles in sleep disorders. It is timely to stimulate new research in this emergent and rapidly growing field of investigation.

Keywords: microglia, sleep, wakefulness, disease models, animal, diseases

\section{INTRODUCTION}

Humans spend approximately a third of their lives sleeping. Sleep is an involuntary process, required to sustain good mental and physical health. During sleep, the brain processes information, consolidates memories, and undergoes a number of maintenance processes that help its function upon waking (Graves et al., 2001; Abel et al., 2013; Tononi and Cirelli, 2014; Vorster and Born, 2015). Loss or restriction of sleep is associated with multiple detrimental consequences (Musiek and Holtzman, 2016; Pires et al., 2016).

Microglia are macrophages derived from the embryonic yolk-sac that permanently reside in the brain alongside neurons, astrocytes, and oligodendrocytes (Gomez Perdiguero et al., 2013). These cells are uniformly distributed and their ramified processes constantly survey the brain parenchyma during normal physiological conditions. Microglia respond to pathology in various manners-they enlarge their cell bodies, increase their mobility, and hyper-ramify or reduce their processes. The microglia field has recently undergone explosive growth, especially since microglial roles in the healthy brain are becoming uncovered (Tremblay et al., 2011; Sierra et al., 2014). These mononuclear phagocytes are now recognized as essential contributors to neuronal survival, synaptic pruning, and dendritic spine formation during development, as well as synaptic maintenance and plasticity, neurogenesis, learning, memory, and cognition into adulthood (Salter and Beggs, 2014; Hong and Stevens, 2016; Tay et al., 2016). As the brain's immune cells, microglia help defend against pathogens, and play pivotal roles in recovery from sickness and injury 
(Kettenmann et al., 2011; Tremblay and Sierra, 2014). Microglia phagocytose cellular debris and release pro- and anti-inflammatory cytokines, trophic factors, and various other molecular mediators, processes critical for adaptation of the brain to the ever-changing environment (Delpech et al., 2015; Shemer et al., 2015; Tian et al., 2017).

Microglia detect changes in homeostasis through their recognition of exogenous or endogenous danger signals, pathogen-associated molecular patterns (PAMPs; small molecular motifs conserved within a class of microbes that are recognized by cells of the innate immune system via pathogen recognition receptors) and danger-associated molecular patterns (DAMPs; host-derived motifs that also regulate the activation of pathogen recognition receptors and can be triggered by enhanced neuronal activity and psychological stress). Microglia respond by orchestrating neuroinflammation through their interactions with peripheral immune cells which invade the brain, especially if the blood-brain-barrier is compromised (notably occurs during chronic sleep restriction, He et al., 2014), as well as vascular cells, glial cells, and neurons (Xanthos and Sandkuhler, 2014). In some contexts, microglia perform adaptive immune functions and present antigens to T cells upon binding to MHC class II expressed on their surface (Greter et al., 2015). Their responses can be homeostatic, leading to adaptation, but also dysfunctional, contributing to, or causing pathology. Anti-inflammatory mechanisms can be triggered in parallel to terminate neuroinflammmation and reduce pathological outcomes (Xanthos and Sandkuhler, 2014).

Considering that sleep and microglia share essential homeostatic functions, we have focused this review to examine the roles of microglial phagocytosis and inflammatory mediators, among various brain regions, in the pathophysiology of sleep disorders (see Table 1 for a summary). Although the number of studies providing direct evidence is currently limited, we anticipate this field of investigation to expand in the near future, considering the exponential growth of microglial research (and increased availability of tools to study these cells specifically) in recent years. Since very interesting findings on the topic recently came out, we also hoped to stimulate further the interest toward microglia and sleep.

\section{Infection-Induced Sleep Gain}

"Sickness" is defined as the conjunction of adaptive changes that are elicited by activation of the immune system. Among those changes, infections induce stereotypic alterations in sleep activity. In rodents, sleep is divided into (1) non-rapid eye-movement (NREM) sleep [a state of deep sleep that is characterized by slow electroencephalogram (EEG) delta $(0.5-4 \mathrm{~Hz})$ waves] and (2) rapid eye-movement (REM) sleep (displaying electrical oscillations typical of brain activation but with inhibition of muscle tone and involuntary saccadic eye movements). During sickness, the ratio of NREM to REM sleep is increased (i.e., time in NREM sleep is increased while time in REM sleep is reduced, Lancel et al., 1995; Kapas et al., 1998; Mullington et al., 2000). A significant increase in the power of slow wave activity (SWA) is also observed (Kapas et al., 1998; Mullington et al., 2000; Majde and Krueger, 2005). SWA is commonly referred to as slow oscillation (Steriade et al., 1993a,b,c; Cowan and Wilson, 1994) and considered a physiological measure of the homeostatic drive for sleep (Borbely, 1982, 2001; Franken et al., 2001). Numerous clinical reports concur that both acute and chronic infections, as well as inflammatory diseases, are associated with sleep-related symptoms such as reduced sleep quality and increased fatigue (for review see Rohleder et al., 2012).

Many pathogens comprising gram-positive and gramnegative bacteria (Toth and Krueger, 1988, 1989; Krueger and Majde, 1994), viruses (influenza virus, rhinovirus, and human immunodeficiency virus) (Norman et al., 1988, 1990; Toth et al., 1995; Opp et al., 1996; Gemma and Opp, 1999), fungal organisms that include Candida albicans and the protozoan Trypanosoma brucei brucei (Kent et al., 1988; Toth and Krueger, 1989; Toth et al., 1994) induce a sleep response (for review, Krueger and Opp, 2016). Infectious agents do so via PAMPs that enhance the systemic and central production of pro-inflammatory cytokines, such as interleukin (IL)-1 and tumor necrosis factor-alpha (TNF $\alpha)$ (Imeri and Opp, 2009; Besedovsky et al., 2012; Krueger and Opp, 2016). IL-1 and TNF $\alpha$ are well-established sleepregulatory substances that regulate NREM sleep duration and intensity by modulating neuronal activity in the hypothalamic preoptic area (Obal and Krueger, 2003), locus coeruleus (De Sarro et al., 1997), dorsal raphe nucleus (Manfridi et al., 2003), and cerebral cortex (Yoshida et al., 2004; Churchill et al., 2008). Hence, these cytokines act both at the circuit level and locally in the cortex and brainstem to promote sleep (Krueger, 2008). All these findings have been extensively reviewed (Krueger, 2008; Krueger et al., 2011; Zielinski et al., 2013; Krueger and Opp, 2016).

Microglia are the main producers of cytokines within the nervous system during inflammatory diseases (Renno et al., 1995; Van Dam et al., 1995; Buttini et al., 1997; Medana et al., 1997; Gregersen et al., 2000; Kettenmann et al., 2011; Delpech et al., 2015), indicating that these cells could play a crucial role in infection-induced sleep alterations. The effects of cytokines on sleep-wake behavior involve communication between neurons and microglia. As microglial processes constantly survey synaptic elements in a neuronal activity-dependent manner (Davalos et al., 2005; Nimmerjahn et al., 2005; Wake et al., 2009; Tremblay et al., 2010; Hristovska and Pascual, 2015), a recent publication hypothesized that pro-inflammatory cytokines may exert their somnogenic effects by promoting microglial attraction to synapses (Karrer et al., 2015). In line with this assumption, the authors found that $\mathrm{TNF} \alpha$ induces neuronal production of the chemokines (chemoattractant cytokines) CCL2, CCL7, and CXCL10, which bind to their receptors expressed by microglia and promote microglial process extension (Karrer et al., 2015). $\mathrm{TNF} \alpha$ additionally upregulates neuronal Homerla (Karrer et al., 2015), which was shown to drive the homeostatic scaling-down of excitatory synapses during sleep (Diering et al., 2017). According to the synaptic homeostasis hypothesis, information processing and decision-making during wakefulness drive strengthening of synapses, which is counterbalanced during sleep by a global weakening (de Vivo et al., 2017). Mice with a deletion of Homerla also show reduced wakefulness with increased NREM sleep during the dark period (Naidoo et al., 2012). While it has yet 
TABLE 1 | Microglial functions and relevance to sleep disorders.

Neuroinflammation cytokines in the central nervous system during inflammatory diseases.
Microglia are the main producers of
Infection-induced sleep gain

$\mathrm{IL}-1$ and TNF $\alpha$ are well-known to promote sleep in humans and in animal models (Krueger, 2008; Krueger et al., 2011; Zielinski et al., 2013; Krueger and Opp, 2016).
Experimental findings

Suggested implication

Pro-inflammatory cytokines may exert somnogenic effects by promoting microglial attraction to synapses (Karrer et al., 2015). TNF $\alpha$ induces the production of chemokines (CCL2, CCL7, and CXCL10) by neurons, which bind to corresponding receptors expressed by microglia and are known to promote microglial process extension (Karrer et al., 2015).

\section{Recreational-drug induced sleep loss}

PET scans of chronic d-METH self-administrating individuals reveals increased binding of the radiotracer $[11 \mathrm{C}](\mathrm{R})$-PK11195 that labels "activated" microglia (McCoy et al., 2007). In mice undergoing microglial depletion, the duration of daily wakefulness produced by d-METH is reduced by nearly $1 \mathrm{~h}$. Ex vivo nitric oxide synthase (NOS) activity, and in vivo NOS expression are also elevated in cortical CD11 ${ }^{+}$microglia from wild-type mice upon acute d-METH exposure. Additionally, $\mathrm{CD} 11 \mathrm{~b}^{+}$cells are the only ones found to exhibit changes in sleep-regulatory IL-1 $\beta$ expression in response to d-METH (Wang et al., 2014).

\section{Narcolepsy}

Increased levels of IL-6 and TNF $\alpha$ are measured in the sera or plasma from narcoleptic patients (Cartier et al., 2005; Eltayeb et al., 2007; Dauvilliers et al., 2014).

Reduced levels of microglia/macrophage-derived CCR1 and CCR3 are measured in peripheral blood samples from narcolepsy patients (Mignot et al., 1995; Tafti et al., 1996; Partinen et al., 2014).

\section{Antigen presentation}

Microglia can present antigens to $T$ cells upon their binding to $\mathrm{MHC}$ class Il expressed on their surface.
An increased microglial expression of $\mathrm{MHC}$ class II is measured in the central nervous system of narcoleptic dogs (Tafti, 2009).
The effects of d-METH on sleep and wakefulness could be mediated partly by microglia, through exacerbated oxidative stress and pro-inflammatory cytokine release (Wang et al., 2014).
Decrease in CCR expression could lead to a defect in the recognition and phagocytosis of damaged cells by microglia and consequently to a delayed resolution of acute inflammation. These defects could lead to enhanced autoimmunity resulting in the loss of hypocretin neurons.

\section{Phagocytosis}

Microglia prune synapses in a complement-dependent manner in contexts of health and disease.
A distinctive complotype, i.e., a combination of polymorphisms defining complement activity: BfS, C4A3, and C4B1, was identified in narcopleptic patients (Savill et al., 2002).
Local infusion of a low-dose of the endotoxin lipopolysaccharide in rats, as a model of chronic inflammation, induces the loss of hypocretin neurons and increases the number of MHC class II-positive microglia in the lateral hypothalamus. Microglia-mediated inflammation might be a trigger for the loss of hypocretin neurons during narcolepsy (Maurovich-Horvat et al., 2014).

Exacerbation of complement-dependent microglia phagocytic activity is a plausible mechanism leading to the loss of hypocretin neurons.

\section{Obstructive sleep apnea}

\section{Sleep fragmentation}

Microglial co-localization with the marker of glutamatergic axon terminals VGLUT1 is increased after 5 days of chronic sleep deprivation in mouse prefrontal cortex (Bellesi et al., 2017). In parallel, the total length of microglial process arborization, and the proportion of the microglial population showing less ramified morphologies, are significantly reduced (Bellesi et al., 2017).
These observations suggest an exacerbated microglial pruning of synapes, which could be mediated by the classical complement pathway considering that expression of the complement protein C3 was concomitantly increased by sleep deprivation (Bellesi et al., 2017). 
TABLE 1 | Continued

\begin{tabular}{|c|c|}
\hline Neuroinflammation & Experimental findings \\
\hline Immune surveillance & Chronic intermittent hypoxia \\
\hline $\begin{array}{l}\text { Microglia detect changes in } \\
\text { homeostasis through their recognition } \\
\text { of exogenous or endogenous danger } \\
\text { signals, such as danger-associated }\end{array}$ & $\begin{array}{l}\text { Elevated levels of DAMPs are measured in blood samples from } \\
\text { obstructive sleep apnea patients (Sapin et al., 2015), as well as in } \\
\text { the hippocampus of rodent models of chronic intermittent hypoxia } \\
\text { (Kiernan et al., 2016). }\end{array}$ \\
\hline
\end{tabular}

Suggested implication

molecular patterns (DAMPs).

to be demonstrated in vivo, these data provide a provocative mechanism by which TNF $\alpha$ could regulate the sleep-wake cycle.

Interestingly, microglia were recently revealed also to follow a circadian rhythm for protein expression that is controlled by their intrinsic molecular clock (Hayashi et al., 2013). This notably affects their production of cytokines (Fonken et al., 2015), and could not only alter their response to infectious agents, but also their influence on sleep.

Overall, the literature suggest microglia play direct (structural interactions with synapses) as well as indirect (release of inflammatory cytokines) roles in infection-induced sleep gain.

\section{Narcolepsy}

Narcolepsy is characterized by excessive daytime sleepiness, sleep/wake fragmentation, hallucinations, sleep paralysis, and disturbed nocturnal sleep. The prevalence of this chronic sleep disorder ranges between 0.02 and $0.05 \%$ of the general population, with first symptoms appearing around 20-30 years of age, preferentially in males. After one or more years of progression, the disease stabilizes (Siegel, 1999; Longstreth et al., 2007). Narcolepsy is caused by a specific loss of hypothalamic hypocretin-producing neurons (85-95\% of cells in humans), which coincides with low hypocretin levels in patients' cerebrospinal fluid (CSF) (Nishino et al., 2000; Thannickal et al., 2000; Mignot et al., 2002). Hypocretin knockout mice recapitulate human disease and are commonly used as an animal model of narcolepsy (Chemelli et al., 1999; Hara et al., 2001; Tabuchi et al., 2014). However, it remains unclear how hypocretin neurons are lost in the human pathophysiology.

Both genetic heritability and environmental triggers were found to be involved in disease progression. The cause and pathogenesis of narcolepsy are still unclear but likely involve the immune system. Human narcolepsy is closely associated (>95\% of cases) with human leukocyte antigen (HLA) class II alleles in the major histocompatibility (MHC) region (Langdon et al., 1984; Matsuki et al., 1992; Mignot et al., 1994; Tafti, 2009), a classical hallmark of autoimmune diseases. Yet, its classification as an autoimmune disease is still a matter of debate (for review, see Mignot et al., 1995; Partinen et al., 2014).

Accumulating evidence allows us to consider a possible microglial implication in narcolepsy. Increased microglial expression of MHC class II (a hallmark of chronic activation) has been reported in the central nervous system (CNS) of narcoleptic dogs. Reactive microglia were predominantly located in the brainstem (including the reticular formation), basal forebrain, and amygdala (Tafti et al., 1996). A recent publication also reported reduced levels of the chemokine receptors CCR1 and CCR3 in peripheral blood samples of patients with narcolepsy (Cartier et al., 2005; Eltayeb et al., 2007; Toyoda et al., 2015). These receptors are expressed by microglia (in the brain) and other macrophages (in the bloodstream and other tissues) to ensure proper and coordinated inflammatory responses. It is hypothesized that a decrease in CCR expression leads to a defect in the recognition and phagocytosis of damaged cells by microglia and consequently to a delayed resolution of acute inflammation. These defects could lead to enhanced autoimmunity resulting in the loss of hypocretin neurons.

Clinical studies have also revealed that narcolepsy patients have subtly dysregulated cytokine levels in their serum and CSF consistent with markers of microglial reactivity (Okun et al., 2004; Dauvilliers et al., 2014; Maurovich-Horvat et al., 2014; Tanaka et al., 2014). Multiple independent studies that include different ethnic populations showed a preponderant increase in IL-6 and TNF $\alpha$ expression in sera or plasma from patients with narcolepsy (Okun et al., 2004; Maurovich-Horvat et al., 2014; Tanaka et al., 2014). Other studies have identified changes in IL-4 (Dauvilliers et al., 2014) or IL-8 (Tanaka et al., 2014) levels. To further assess the role of inflammation in the degeneration of hypocretin neurons, Gerashchenko et al. (Gerashchenko and Shiromani, 2004) infused a lowdose of the endotoxin lipopolysaccharide (LPS) in the lateral hypothalamus of rats as a model of local chronic inflammation. This induced a decline in the number of neurons, including hypocretin neurons, in the lateral hypothalamus. Chronic LPS infusion also increased the number of MHC class II-positive microglia in the lateral hypothalamus. These data suggest that microglia-mediated inflammation might be a trigger for the loss of hypocretin neurons during narcolepsy (Gerashchenko and Shiromani, 2004).

In addition to their important roles in inflammation and immune response, microglia are the main phagocytes of the brain (Sierra et al., 2013). Microglial phagocytosis is a pivotal mechanism for the clearance of cellular elements in the CNS, as demonstrated by their ability to engulf brainspecific cargo, such as axonal and myelin debris or apoptotic neurons. Additionally, recent data has shown that microglia can execute neuronal death by phagocytosing stressed-but-viable neurons, a process termed "phagoptosis" (Brown and Neher, 2014). Microglia are equipped with a complementary array of receptors enabling them to recognize their targets (the 
so-called "eat-me" signals) including proteins of the classical complement cascade (Savill et al., 2002; Ravichandran, 2010). Interestingly, a clinical study reported a correlation between narcolepsy and complement receptors (Cuccia et al., 1991). The thirty narcoleptic patients studied had a distinctive complotype, i.e., a combination of polymorphisms defining complement activity: BfS, C4A3, and C4B1 (Cuccia et al., 1991). One could hypothesize that exacerbation of complement-dependent microglial phagocytic activity is a plausible mechanism leading to the loss of (hypocretin) neurons as also observed in other neurodegenerative conditions such as Alzheimer's disease (Hong et al., 2016).

Overall, this evidence indicates that the homeostatic function of microglia is altered in the pathogenesis of narcolepsy, leading to an increased release of inflammatory factors, and alteration of their phagocytic activity. Both events alter microglia-neuron interactions and might support the degeneration of hypocretin neurons and subsequent sleep alterations.

\section{Obstructive Sleep Apnea: Sleep Fragmentation and Chronic Intermittent Hypoxia}

Obstructive sleep apnea (OSA), often associated with obesity, is a multifactorial systemic disease affecting approximately 10-25\% of the general population worldwide (Peppard et al., 2013; Heinzer et al., 2015; Senaratna et al., 2017). In OSA the upper airways are narrowed or collapsed during sleep causing repetitive pauses of breathing (apneas) and concomitant reductions of blood oxygen level. Apneas are followed by increased breathing efforts, which in turn lead to episodic increases in blood carbon dioxide concentration. These events cause repeated arousals from sleep (sleep fragmentation) and/or excessive daytime sleepiness. OSA is often accompanied by neurocognitive dysfunction leading to impairments in attention and vigilance, learning, and memory, as well as executive functions (Zhou et al., 2016). If untreated, OSA associates with several comorbidities (Vijayan, 2012) such as cardiovascular disease (Sanchez-de-laTorre et al., 2013) and metabolic syndrome, including obesity (Shechter, 2016) and insulin resistance (Ip et al., 2002), as well as mild cognitive impairment/dementia (Yaffe et al., 2011, 2014). Recent epidemiological studies also indicated that OSA may be associated with an increased risk of cancer (Nieto et al., 2012; Palamaner Subash Shantha et al., 2015; Gozal et al., 2016).

The two major acute pathophysiological consequences of OSA are: (1) tissue oxygen shortage/hypoxia with rapid reoxygenation (i.e., chronic intermittent hypoxia, $\mathrm{CIH}$ ) and (2) sleep fragmentation (SF) (Young et al., 1993). In OSA, most tissues, including the brain, are repeatedly exposed to reduced oxygen levels or a total lack of oxygen followed by rapid increases in oxygen availability. This pattern of repeated hypoxia-reoxygenation (HRO) increases tissue levels of reactive oxygen species/reactive nitrogen species (ROS/RNS) and concomitantly activates the immune response as measured by the production of pro-inflammatory cytokines (Lavie, 2003, 2015). However, these cellular responses are not uniform across all tissues and vary with the severity of OSA.

In OSA patients, the poor health outcomes are a consequence of complex interactions between $\mathrm{CIH}$ and SF. However, with animal models it has been possible to begin dissecting the individual pathophysiological contributions of SF and tissue oxygenation. In the next sections we review each of them separately in light of a hypothesized microglial contribution.

\section{Chronic Intermittent Hypoxia}

Because the HRO processes in OSA are similar to the ischemiareperfusion events in a wide range of brain pathologies, data from these disease models provide valuable information regarding the cellular signaling pathways which are possibly involved. However, it should be noted that in OSA, the tissue exposures to hypoxia are cyclic, and most importantly chronic, and therefore the cellular responses can differ substantially from those of acute exposures (Almendros et al., 2014). The main trigger of the inflammatory response measured in $\mathrm{CIH}$ is oxidative stress (Wang et al., 2010), defined as an imbalance between pro-oxidant and anti-oxidant systems, resulting in an excessive production of ROS such as superoxide, hydrogen peroxide, and various RNS (Lavie, 2015). ROS damage critical cellular biomolecules thus leading to cell injury or death. In OSA models of $\mathrm{CIH}$, signs of injured cells have been reported in various brain areas but the hippocampus and cerebral cortex appear to be most sensitive (Gozal et al., 2001; Xu et al., 2004). These lesions were proposed to contribute to the widespread neurocognitive defects encountered in OSA (Lim and Veasey, 2010; Harper et al., 2013).

Evidence of microglial phenotypic transformation such as microglia-specific inflammatory gene expression as well as morphological changes have been reported in $\mathrm{CIH}$ models of OSA (Smith et al., 2013; Sapin et al., 2015). A recent review (Kiernan et al., 2016) posits several putative mechanisms by which microglial physiological functions, which are now recognized to be crucial for plasticity, learning, and memory, may be affected by $\mathrm{CIH}$ pathophysiology:

(i) By ROS. Either directly (although this hypothesis was not yet confirmed) or indirectly, by local signals generated by ROS injured/dying neurons.

(ii) By peripheral inflammation, a condition well established in OSA (Unnikrishnan et al., 2015). Signals of inflammation could reach microglia via neural transmission of vagal afferents reacting to circulating pro-inflammatory agents or the pro-inflammatory agents themselves could cross the blood-brain barrier to directly affect microglia.

(iii) By responding to DAMPs such as HSP60, HMGB1, and MRP8/14. Elevated levels of DAMPs have been reported in blood samples from OSA patients (Wu et al., 2010), as well as in the hippocampus of rodent models of CIH (Gozal et al., 2002).

\section{Sleep Fragmentation}

There is a growing literature indicating that short or insufficient sleep is associated with low grade inflammation (Everson, 2005; Mullington et al., 2010; Aho et al., 2013) as well as cellular 
stress (Naidoo, 2012; Hakim et al., 2015). Recently, findings from longitudinal follow-up studies in patients with idiopathic REM sleep behavior disorder also revealed that most patients eventually develop neurodegenerative disorder, particularly Parkinson's disease or other synucleopathies (Stokholm et al., 2017). Positron emission tomography (PET scan) studies using the radiotracer $\left[{ }^{11} \mathrm{C}\right](R)-\mathrm{PK} 11195$, which labels "translocator protein $18 \mathrm{kDa}$ (TSPO)," mainly expressed by microglia (Banati, 2002) and considered to modulate their inflammatory activity and phagocytosis (Karlstetter et al., 2014), revealed an increased binding of the radiotracer in the substantia nigra of patients with idiopathic REM sleep behavior disorder, thus identifying microglial "activation" as a potential therapeutic target for halting or delaying the neurodegenerative process.

Two experimental studies in rodent models of chronic sleep deprivation have also reported microglial morphological changes that comprise the enlargement of their cell body (Hsu et al., 2003) and increased expression of pro-inflammatory cytokines (Wisor et al., 2011a). Very recently, Bellesi et al. revealed using confocal microscopy analysis that microglial homeostatic surveillance of the parenchyma is reduced after 5 days of chronic sleep deprivation in mouse prefrontal cortex. The total length of microglial process arborization and the proportion of microglial cells showing ramified morphologies were significantly reduced. These changes were accompanied by an increased microglial co-localization with the marker of glutamatergic axon terminals VGLUT1, suggesting exacerbated phagocytosis, which could be mediated by the classical complement pathway considering that expression of the complement protein C3 targeting synapses for elimination (Schafer et al., 2012) was concomitantly increased by sleep deprivation (Bellesi et al., 2017). Expression of the TAM receptor MERTK, which regulates microglial surveillance of the parenchyma and phagocytic behavior under physiological conditions (Fourgeaud et al., 2016), was also found to be increased by sleep deprivation (Bellesi et al., 2017). Interestingly, astrocytes were additionally shown in Bellesi et al., using high-resolution serial block-face scanning electron microscopy, to phagocytose synaptic elements, mainly presynaptic axon terminals, both after acute and chronic sleep deprivation (Bellesi et al., 2017). Glial cells reactivity thus appears to be implicated in the detrimental consequences of sleep loss, through neuronal circuit remodeling or loss of their essential physiological functions. Synaptic loss is considered the best pathological correlate of cognitive decline across a variety of conditions that include aging and neurodegenerative diseases (Duman and Aghajanian, 2012; Spires-Jones and Hyman, 2014).

In the case of OSA, however, the main sleep phenotype is SF (rather than sleep loss) coupled with an excessive daytime sleepiness and widespread cognitive dysfunction. In the last decade rodent models of SF have demonstrated that SF alone (without $\mathrm{CIH}$ ) induces sleepiness and cognitive impairment (McCoy et al., 2007; McKenna et al., 2007; Tansey et al., 2007; Tartar et al., 2010; Ramesh et al., 2012), obesity (Wang et al., 2014), immune mediated metabolic dysfunction (Zhang et al., 2014), cardiovascular alterations (Carreras et al., 2014), and alterations of the gut microbiota
(Poroyko et al., 2016). All of these consequences have an oxidative stress-mediated inflammatory component that could directly or indirectly affect microglial functions as proposed for $\mathrm{CIH}$ above. Gut microbiota can also directly influence microglial maturation, leading for instance to an attenuated production of pro-inflammatory cytokines upon immune stimulation (Erny et al., 2015). In addition, SF mediated increase in microglial surveillance of synaptic elements or remodeling of neuronal circuits could underlie some of the reported impairments in cognitive performance through synaptic loss.

\section{Recreational-Drug Induced Sleep Loss}

Recreational drugs have deleterious consequences on sleep, with dextro-methamphetamine (d-METH) exerting its sustained wake-promoting effects (for up to several days) by elevating the monoaminergic tone. It is rarely prescribed due to concerns involving neurotoxicity, notably to dopaminergic and serotoninergic neurons, in addition to its aphrodisiac and euphoriant effects, among other mind-altering properties, and strong addictiveness. PET scans of chronic d-METH self-administrating individuals using the radiotracer $\left[{ }^{11} \mathrm{C}\right](R)$ PK11195 revealed exacerbated microglial reactivity across several brain regions that receive dopaminergic or serotoninergic innervation, including the midbrain, striatum, thalamus, orbitofrontal, and insular cortices (Sekine et al., 2008). This microglial transformation is likely plastic and reverts to normal over longer periods of abstinence, since the binding levels of $\left[{ }^{11} \mathrm{C}\right](R)$-PK11195 correlated inversely with the duration of withdrawal in d-METH abusers (Sekine et al., 2008).

The effects of d-METH on sleep and wakefulness could be mediated by microglia, through exacerbated oxidative stress and pro-inflammatory cytokine release (Wisor et al., 2011b). In mice undergoing microglial depletion [through delivery of ganciclovir in transgenics expressing the suicide agent herpes thymidine kinase under control of the CD11b promoter], the duration of daily wakefulness produced by d-METH was reduced by nearly 1 h. Ex vivo nitric oxide synthase (NOS) activity, and in vivo NOS expression were also elevated in cortical $\mathrm{CD}_{11} \mathrm{~b}^{+}$microglia from wild-type mice upon acute d-METH exposure. Additionally, $\mathrm{CD}_{11} \mathrm{~b}^{+}$cells, which mainly comprise microglia in the brain, were the only ones among the cerebral cortex found to exhibit changes in sleep-regulatory IL- $1 \beta$ pro-inflammatory cytokine expression in response to d-METH (Wisor et al., 2011b). In a follow up study by the same group, it was further shown that IL-1 receptor $(\mathrm{R})$ deficiency potentiates, although modestly, the wakepromoting effects of d-METH (Schmidt and Wisor, 2012). The increased time spent in NREM sleep subsequent to d-METHinduced wakefulness was abolished in IL-1R knockout mice, while the increased time spent asleep after $3 \mathrm{~h}$ of behaviorally enforced wakefulness was similarly prevented in the knockouts. These findings indicate that microglial IL-1 $\beta$ signaling through IL-1R contributes to the hypersomnolence that ensues sleep loss, whether it is triggered pharmacologically by recreational drugs or through behaviorally-induced sleep deprivation (Schmidt and Wisor, 2012). 


\section{CONCLUSION AND PERSPECTIVES}

While microglial function was not a primary focus in several of the studies covered in this review, their overall findings indicate that microglial dysfunction (in the form of exacerbated phagocytic activity and neuroinflammation) may contribute to the pathophysiology of sleep disorders. These activities would be exerted in concert with other brain cells, vascular, glial, or neuronal, and the peripheral immune cells transiting to the brain. In light of these combined findings, substantial amount of evidence point toward an emerging role for neuroinflammatory processes in the pathophysiology of sleep disorders. Microglial (and astrocytic) phagocytosis of synaptic elements was also found to be exacerbated in rodent models of sleep deprivation, indicating their possible implication in its detrimental consequences on cognition. Microglia thus emerge as an important subject of investigation for future sleep-related studies, as already recognized in a variety of neuropsychiatric and neurodegenerative contexts. In addition to the diseases discussed in this review, it would be interesting to study the roles of microglia in the regulation of sleep functions: their contribution to memory consolidation and transformation (Dudai et al., 2015), synaptic homeostasis which downscales synapses during sleep

\section{REFERENCES}

Abel, T., Havekes, R., Saletin, J. M., and Walker, M. P. (2013). Sleep, plasticity and memory from molecules to whole-brain networks. Curr. Biol. 23, R774-R788. doi: 10.1016/j.cub.2013.07.025

Aho, V., Ollila, H. M., Rantanen, V., Kronholm, E., Surakka, I., van Leeuwen, W. M., et al. (2013). Partial sleep restriction activates immune responserelated gene expression pathways: experimental and epidemiological studies in humans. PLoS ONE 8:e77184. doi: 10.1371/journal.pone.0077184

Almendros, I., Wang, Y., and Gozal, D. (2014). The polymorphic and contradictory aspects of intermittent hypoxia. Am. J. Physiol. Lung Cell. Mol. Physiol. 307 L129-L140. doi: 10.1152/ajplung.00089.2014

Banati, R. B. (2002). Visualising microglial activation in vivo. Glia 40, 206-217. doi: $10.1002 /$ glia.10144

Bellesi, M., de Vivo, L., Chini, M., Gilli, F., Tononi, G., and Cirelli, C. (2017). Sleep loss promotes astrocytic phagocytosis and microglial activation in mouse cerebral cortex. J. Neurosci. 37, 5263-5273. doi: 10.1523/JNEUROSCI.3981-16.2017

Besedovsky, L., Lange, T., and Born, J. (2012). Sleep and immune function. Pflugers Arch. 463, 121-137. doi: 10.1007/s00424-011-1044-0

Borbely, A. A. (1982). A two process model of sleep regulation. Hum. Neurobiol. 1, 195-204.

Borbely, A. A. (2001). From slow waves to sleep homeostasis: new perspectives. Arch. Ital. Biol. 139, 53-61. doi: 10.4449/aib.v139i1.204

Brown, G. C., and Neher, J. J. (2014). Microglial phagocytosis of live neurons. Nat. Rev. Neurosci. 15, 209-216. doi: 10.1038/nrn3710

Buttini, M., Mir, A., Appel, K., Wiederhold, K. H., Limonta, S., Gebicke-Haerter, P. J., et al. (1997). Lipopolysaccharide induces expression of tumour necrosis factor alpha in rat brain: inhibition by methylprednisolone and by rolipram. Br. J. Pharmacol. 122, 1483-1489. doi: 10.1038/sj.bjp.0701502

Carreras, A., Zhang, S. X., Peris, E., Qiao, Z., Gileles-Hillel, A., Li, R. C., et al. (2014). Chronic sleep fragmentation induces endothelial dysfunction and structural vascular changes in mice. Sleep 37, 1817-1824. doi: $10.5665 /$ sleep. 4178

Cartier, L., Hartley, O., Dubois-Dauphin, M., and Krause, K. H. (2005). Chemokine receptors in the central nervous system: role in brain inflammation to ensure learning during wake (Tononi and Cirelli, 2014), and the brain clearance from its toxic metabolites during sleep, in cooperation with astrocytes, which form a system of perivascular tunnels named the "glymphatics" (Xie et al., 2013).

\section{AUTHOR CONTRIBUTIONS}

AN, HW, and MET contributed to the design, documentation, and writing of this review article.

\section{FUNDING}

AN is financially supported by INRA, University of Bordeaux and Agence Nationale de la Recherche; HW by the Academy of Finland; and MET by the Canadian Institutes of Health Research. MET also holds a Canada Research Chair (Tier 2) in Neuroimmune Plasticity in Health and Therapy.

\section{ACKNOWLEDGMENTS}

We are grateful to Julie C. Savage for her insightful revision of our manuscript. and neurodegenerative diseases. Brain Res. Brain Res. Rev. 48, 16-42. doi: 10.1016/j.brainresrev.2004.07.021

Chemelli, R. M., Willie, J. T., Sinton, C. M., Elmquist, J. K., Scammell, T., Lee, C., et al. (1999). Narcolepsy in orexin knockout mice: molecular genetics of sleep regulation. Cell 98, 437-451. doi: 10.1016/S0092-8674(00)81973-X

Churchill, L., Rector, D. M., Yasuda, K., Fix, C., Rojas, M. J., Yasuda, T., et al. (2008). Tumor necrosis factor alpha: activity dependent expression and promotion of cortical column sleep in rats. Neuroscience 156, 71-80. doi: 10.1016/j.neuroscience.2008.06.066

Cowan, R. L., and Wilson, C. J. (1994). Spontaneous firing patterns and axonal projections of single corticostriatal neurons in the rat medial agranular cortex. J. Neurophysiol. 71, 17-32.

Cuccia, M., Finco, O., Conte, R., Cirignotta, F., and Ruberto, G. (1991). HLA complement markers in Italian narcoleptic patients with special emphasis on BfF subtyping. Complement Inflamm. 8, 86-91.

Dauvilliers, Y., Jaussent, I., Lecendreux, M., Scholz, S., Bayard, S., Cristol, J. P., et al. (2014). Cerebrospinal fluid and serum cytokine profiles in narcolepsy with cataplexy: a case-control study. Brain Behav. Immun. 37, 260-266. doi: 10.1016/j.bbi.2013.12.019

Davalos, D., Grutzendler, J., Yang, G., Kim, J. V., Zuo, Y., Jung, S., et al. (2005). ATP mediates rapid microglial response to local brain injury in vivo. Nat. Neurosci. 8, 752-758. doi: 10.1038/nn1472

Delpech, J. C., Saucisse, N., Parkes, S. L., Lacabanne, C., Aubert, A., Casenave, F., et al. (2015). Microglial activation enhances associative taste memory through purinergic modulation of glutamatergic neurotransmission. J. Neurosci. 35, 3022-3033. doi: 10.1523/JNEUROSCI.3028-14.2015

De Sarro, G., Gareri, P., Sinopoli, V. A., David, E., and Rotiroti, D. (1997). Comparative, behavioural and electrocortical effects of tumor necrosis factoralpha and interleukin-1 microinjected into the locus coeruleus of rat. Life Sci. 60, 555-564. doi: 10.1016/S0024-3205(96)00692-3

de Vivo, L., Bellesi, M., Marshall, W., Bushong, E. A., Ellisman, M. H., Tononi, G., et al. (2017). Ultrastructural evidence for synaptic scaling across the wake/sleep cycle. Science 355, 507-510. doi: 10.1126/science.aah5982

Diering, G. H., Nirujogi, R. S., Roth, R. H., Worley, P. F., Pandey, A., and Huganir, R. L. (2017). Homerla drives homeostatic scaling-down of excitatory synapses during sleep. Science 355, 511-515. doi: 10.1126/science.aai8355 
Dudai, Y., Karni, A., and Born, J. (2015). The consolidation and transformation of memory. Neuron 88, 20-32. doi: 10.1016/j.neuron.2015.09.004

Duman, R. S., and Aghajanian, G. K. (2012). Synaptic dysfunction in depression: potential therapeutic targets. Science 338, 68-72. doi: 10.1126/science.1222939

Eltayeb, S., Berg, A. L., Lassmann, H., Wallstrom, E., Nilsson, M., Olsson, T., et al. (2007). Temporal expression and cellular origin of CC chemokine receptors CCR1, CCR2 and CCR5 in the central nervous system: insight into mechanisms of MOG-induced EAE. J. Neuroinflammation 4:14. doi: 10.1186/1742-2094-4-14

Erny, D., Hrabe de Angelis, A. L., Jaitin, D., Wieghofer, P., Staszewski, O., David, E., et al. (2015). Host microbiota constantly control maturation and function of microglia in the CNS. Nat. Neurosci. 18, 965-977. doi: 10.1038/nn.4030

Everson, C. A. (2005). Clinical assessment of blood leukocytes, serum cytokines, and serum immunoglobulins as responses to sleep deprivation in laboratory rats. Am. J. Physiol. Regul. Integr. Comp. Physiol. 289, R1054-R1063. doi: 10.1152/ajpregu.00021.2005

Fonken, L. K., Frank, M. G., Kitt, M. M., Barrientos, R. M., Watkins, L. R., and Maier, S. F. (2015). Microglia inflammatory responses are controlled by an intrinsic circadian clock. Brain Behav. Immun. 45, 171-179. doi: 10.1016/j.bbi.2014.11.009

Fourgeaud, L., Traves, P. G., Tufail, Y., Leal-Bailey, H., Lew, E. D., Burrola, P. G., et al. (2016). TAM receptors regulate multiple features of microglial physiology. Nature 532, 240-244. doi: 10.1038/nature 17630

Franken, P., Chollet, D., and Tafti, M. (2001). The homeostatic regulation of sleep need is under genetic control. J. Neurosci. 21, 2610-2621.

Gemma, C., and Opp, M. R. (1999). Human immunodeficiency virus glycoproteins 160 and 41 alter sleep and brain temperature of rats. J. Neuroimmunol. 97, 94-101. doi: 10.1016/S0165-5728(99)00052-1

Gerashchenko, D., and Shiromani, P. J. (2004). Effects of inflammation produced by chronic lipopolysaccharide administration on the survival of hypocretin neurons and sleep. Brain Res. 1019, 162-169. doi: 10.1016/j.brainres.2004.06.016

Gomez Perdiguero, E., Schulz, C., and Geissmann, F. (2013). Development and homeostasis of "resident" myeloid cells: the case of the microglia. Glia 61, 112-120. doi: 10.1002/glia.22393

Gozal, D., Daniel, J. M., and Dohanich, G. P. (2001). Behavioral and anatomical correlates of chronic episodic hypoxia during sleep in the rat. J. Neurosci. 21, 2442-2450.

Gozal, D., Ham, S. A., and Mokhlesi, B. (2016). Sleep apnea and cancer: analysis of a nationwide population sample. Sleep 39, 1493-1500. doi: 10.5665/sleep.6004

Gozal, E., Gozal, D., Pierce, W. M., Thongboonkerd, V., Scherzer, J. A., Sachleben, L. R. Jr., et al. (2002). Proteomic analysis of CA1 and CA3 regions of rat hippocampus and differential susceptibility to intermittent hypoxia. J. Neurochem. 83, 331-345. doi: 10.1046/j.1471-4159.2002.01134.x

Graves, L., Pack, A., and Abel, T. (2001). Sleep and memory: a molecular perspective. Trends Neurosci. 24, 237-243. doi: 10.1016/S0166-2236(00) 01744-6

Gregersen, R., Lambertsen, K., and Finsen, B. (2000). Microglia and macrophages are the major source of tumor necrosis factor in permanent middle cerebral artery occlusion in mice. J. Cereb. Blood Flow Metab. 20, 53-65. doi: 10.1097/00004647-200001000-00009

Greter, M., Lelios, I., and Croxford, A. L. (2015). Microglia versus myeloid cell nomenclature during brain inflammation. Front. Immunol. 6:249. doi: 10.3389/fimmu.2015.00249

Hakim, F., Wang, Y., Carreras, A., Hirotsu, C., Zhang, J., Peris, E., et al. (2015). Chronic sleep fragmentation during the sleep period induces hypothalamic endoplasmic reticulum stress and PTP1b-mediated leptin resistance in male mice. Sleep 38, 31-40. doi: 10.5665/sleep.4320

Hara, J., Beuckmann, C. T., Nambu, T., Willie, J. T., Chemelli, R. M., Sinton, C. M., et al. (2001). Genetic ablation of orexin neurons in mice results in narcolepsy, hypophagia, and obesity. Neuron 30, 345-354. doi: 10.1016/S0896-6273(01)00293-8

Harper, R. M., Kumar, R., Ogren, J. A., and Macey, P. M. (2013). Sleep-disordered breathing: effects on brain structure and function. Respir. Physiol. Neurobiol. 188, 383-391. doi: 10.1016/j.resp.2013.04.021

Hayashi, Y., Koyanagi, S., Kusunose, N., Okada, R., Wu, Z., Tozaki-Saitoh, H., et al. (2013). The intrinsic microglial molecular clock controls synaptic strength via the circadian expression of cathepsin S. Sci. Rep. 3:2744. doi: 10.1038/srep02744
He, J., Hsuchou, H., He, Y., Kastin, A. J., Wang, Y., and Pan, W. (2014). Sleep restriction impairs blood-brain barrier function. J. Neurosci. 34, 14697-14706. doi: 10.1523/JNEUROSCI.2111-14.2014

Heinzer, R., Vat, S., Marques-Vidal, P., Marti-Soler, H., Andries, D., Tobback, N., et al. (2015). Prevalence of sleep-disordered breathing in the general population: the HypnoLaus study. Lancet Respir. Med. 3, 310-318. doi: 10.1016/S2213-2600(15)00043-0

Hong, S., Beja-Glasser, V. F., Nfonoyim, B. M., Frouin, A., Li, S., Ramakrishnan, S., et al. (2016). Complement and microglia mediate early synapse loss in Alzheimer mouse models. Science 352, 712-716. doi: 10.1126/science.aad8373

Hong, S., and Stevens, B. (2016). Microglia: phagocytosing to clear sculpt, and eliminate. Dev. Cell 38, 126-128. doi: 10.1016/j.devcel.2016. 07.006

Hristovska, I., and Pascual, O. (2015). Deciphering resting microglial morphology and process motility from a synaptic prospect. Front. Integr. Neurosci. 9:73. doi: 10.3389/fnint.2015.00073

Hsu, J. C., Lee, Y. S., Chang, C. N., Chuang, H. L., Ling, E. A., and Lan, C. T. (2003). Sleep deprivation inhibits expression of NADPH-d and NOS while activating microglia and astroglia in the rat hippocampus. Cells Tissues Organs 173, 242-254. doi: 10.1159/000070380

Imeri, L., and Opp, M. R. (2009). How (and why) the immune system makes us sleep. Nat. Rev. Neurosci. 10, 199-210. doi: 10.1038/nrn2576

Ip, M. S., Lam, B., Ng, M. M., Lam, W. K., Tsang, K. W., and Lam, K. S. (2002). Obstructive sleep apnea is independently associated with insulin resistance. Am. J. Respir. Crit. Care Med. 165, 670-676. doi: 10.1164/ajrccm.165.5. 2103001

Kapas, L., Hansen, M. K., Chang, H. Y., and Krueger, J. M. (1998). Vagotomy attenuates but does not prevent the somnogenic and febrile effects of lipopolysaccharide in rats. Am. J. Physiol. 274, R406-R411.

Karlstetter, M., Nothdurfter, C., Aslanidis, A., Moeller, K., Horn, F., Scholz, R., et al. (2014). Translocator protein $(18 \mathrm{kDa})$ (TSPO) is expressed in reactive retinal microglia and modulates microglial inflammation and phagocytosis. $J$. Neuroinflammation 11:3. doi: 10.1186/1742-2094-11-3

Karrer, M., Lopez, M. A., Meier, D., Mikhail, C., Ogunshola, O. O., Muller, A. F., et al. (2015). Cytokine-induced sleep: neurons respond to TNF with production of chemokines and increased expression of Homerla in vitro. Brain Behav. Immun. 47, 186-192. doi: 10.1016/j.bbi.2014.11.008

Kent, S., Price, M., and Satinoff, E. (1988). Fever alters characteristics of sleep in rats. Physiol. Behav. 44, 709-715. doi: 10.1016/0031-9384(88)90051-0

Kettenmann, H., Hanisch, U. K., Noda, M., and Verkhratsky, A. (2011). Physiology of microglia. Physiol. Rev. 91, 461-553. doi: 10.1152/physrev.00011.2010

Kiernan, E. A., Smith, S. M., Mitchell, G. S., and Watters, J. J. (2016). Mechanisms of microglial activation in models of inflammation and hypoxia: implications for chronic intermittent hypoxia. J. Physiol. 594, 1563-1577. doi: 10.1113/JP271502

Krueger, J. M. (2008). The role of cytokines in sleep regulation. Curr. Pharm. Des. 14, 3408-3416. doi: 10.2174/138161208786549281

Krueger, J. M., Clinton, J. M., Winters, B. D., Zielinski, M. R., Taishi, P., Jewett, K. A., et al. (2011). Involvement of cytokines in slow wave sleep. Prog. Brain Res. 193, 39-47. doi: 10.1016/B978-0-444-53839-0.00003-X

Krueger, J. M., and Majde, J. A. (1994). Microbial products and cytokines in sleep and fever regulation. Crit. Rev. Immunol. 14, 355-379. doi: 10.1615/CritRevImmunol.v14.i3-4.70

Krueger, J. M., and Opp, M. R. (2016). Sleep and Microbes. Int. Rev. Neurobiol. 131, 207-225. doi: 10.1016/bs.irn.2016.07.003

Lancel, M., Cronlein, J., Muller-Preuss, P., and Holsboer, F. (1995) Lipopolysaccharide increases EEG delta activity within non-REM sleep and disrupts sleep continuity in rats. Am. J. Physiol. 268, R1310-R1318.

Langdon, N., Welsh, K. I., van Dam, M., Vaughan, R. W., and Parkes, D. (1984). Genetic markers in narcolepsy. Lancet 2, 1178-1180. doi: 10.1016/S0140-6736(84)92742-9

Lavie, L. (2003). Obstructive sleep apnoea syndrome-an oxidative stress disorder. Sleep Med. Rev. 7, 35-51. doi: 10.1053/smrv.2002.0261

Lavie, L. (2015). Oxidative stress in obstructive sleep apnea and intermittent hypoxia-revisited-the bad ugly and good: implications to the heart and brain. Sleep Med. Rev. 20, 27-45. doi: 10.1016/j.smrv.2014.07.003

Lim, D. C., and Veasey, S. C. (2010). Neural injury in sleep apnea. Curr. Neurol. Neurosci. Rep. 10, 47-52. doi: 10.1007/s11910-009-0078-6 
Longstreth, W. T. Jr., Koepsell, T. D., Ton, T. G., Hendrickson, A. F., and van Belle, G. (2007). The epidemiology of narcolepsy. Sleep 30, 13-26. doi: $10.1093 /$ sleep/30.1.13

Majde, J. A., and Krueger, J. M. (2005). Links between the innate immune system and sleep. J. Allergy Clin. Immunol. 116, 1188-1198. doi: 10.1016/j.jaci.2005.08.005

Manfridi, A., Brambilla, D., Bianchi, S., Mariotti, M., Opp, M. R., and Imeri, L. (2003). Interleukin-1beta enhances non-rapid eye movement sleep when microinjected into the dorsal raphe nucleus and inhibits serotonergic neurons in vitro. Eur. J. Neurosci. 18, 1041-1049. doi: 10.1046/j.1460-9568.2003.02836.x

Matsuki, K., Grumet, F. C., Lin, X., Gelb, M., Guilleminault, C., Dement, W. C., et al. (1992). DQ (rather than DR) gene marks susceptibility to narcolepsy. Lancet 339:1052. doi: 10.1016/0140-6736(92)90571-J

Maurovich-Horvat, E., Keckeis, M., Lattova, Z., Kemlink, D., Wetter, T. C., Schuld, A., et al. (2014). Hypothalamo-pituitary-adrenal axis, glucose metabolism and TNF-alpha in narcolepsy. J. Sleep Res. 23, 425-431. doi: 10.1111/jsr.12138

McCoy, J. G., Tartar, J. L., Bebis, A. C., Ward, C. P., McKenna, J. T., Baxter, M. G., et al. (2007). Experimental sleep fragmentation impairs attentional set-shifting in rats. Sleep 30, 52-60. doi: 10.1093/sleep/30.1.52

McKenna, J. T., Tartar, J. L., Ward, C. P., Thakkar, M. M., Cordeira, J. W., McCarley, R. W., et al. (2007). Sleep fragmentation elevates behavioral, electrographic and neurochemical measures of sleepiness. Neuroscience 146, 1462-1473. doi: 10.1016/j.neuroscience.2007.03.009

Medana, I. M., Hunt, N. H., and Chaudhri, G. (1997). Tumor necrosis factoralpha expression in the brain during fatal murine cerebral malaria: evidence for production by microglia and astrocytes. Am. J. Pathol. 150, 1473-1486.

Mignot, E., Lammers, G. J., Ripley, B., Okun, M., Nevsimalova, S., Overeem, S., et al. (2002). The role of cerebrospinal fluid hypocretin measurement in the diagnosis of narcolepsy and other hypersomnias. Arch. Neurol. 59, 1553-1562. doi: 10.1001/archneur.59.10.1553

Mignot, E., Lin, X., Arrigoni, J., Macaubas, C., Olive, F., Hallmayer, J., et al. (1994). DQB1 $* 0602$ and $\mathrm{DQA} 1 * 0102$ (DQ1) are better markers than DR2 for narcolepsy in Caucasian and black Americans. Sleep 17, S60-S67. doi: 10.1093/sleep/17.suppl_8.S60

Mignot, E., Tafti, M., Dement, W. C., and Grumet, F. C. (1995). Narcolepsy and immunity. Adv. Neuroimmunol. 5, 23-37. doi: 10.1016/0960-5428(94)00043-N

Mullington, J., Korth, C., Hermann, D. M., Orth, A., Galanos, C., Holsboer, F., et al. (2000). Dose-dependent effects of endotoxin on human sleep. Am. J. Physiol. Regul. Integr. Comp. Physiol. 278, R947-R955.

Mullington, J. M., Simpson, N. S., Meier-Ewert, H. K., and Haack, M. (2010). Sleep loss and inflammation. Best Pract. Res. Clin. Endocrinol. Metab. 24, 775-784. doi: 10.1016/j.beem.2010.08.014

Musiek, E. S., and Holtzman, D. M. (2016). Mechanisms linking circadian clocks, sleep, and neurodegeneration. Science 354, 1004-1008. doi: $10.1126 /$ science.aah4968

Naidoo, N. (2012). Roles of endoplasmic reticulum and energetic stress in disturbed sleep. Neuromol. Med. 14, 213-219. doi: 10.1007/s12017-012-8179-9

Naidoo, N., Ferber, M., Galante, R. J., McShane, B., Hu, J. H., Zimmerman, J., et al. (2012). Role of Homer proteins in the maintenance of sleep-wake states. PLoS ONE 7:e35174. doi: 10.1371/journal.pone.0035174

Nieto, F. J., Peppard, P. E., Young, T., Finn, L., Hla, K. M., and Farre, R. (2012). Sleep-disordered breathing and cancer mortality: results from the Wisconsin Sleep Cohort Study. Am. J. Respir. Crit. Care Med. 186, 190-194. doi: 10.1164/rccm.201201-0130OC

Nimmerjahn, A., Kirchhoff, F., and Helmchen, F. (2005). Resting microglial cells are highly dynamic surveillants of brain parenchyma in vivo. Science 308, 1314-1318. doi: 10.1126/science.1110647

Nishino, S., Ripley, B., Overeem, S., Lammers, G. J., and Mignot, E. (2000). Hypocretin (orexin) deficiency in human narcolepsy. Lancet 355, 39-40. doi: 10.1016/S0140-6736(99)05582-8

Norman, S. E., Chediak, A. D., Kiel, M., and Cohn, M. A. (1990). Sleep disturbances in HIV-infected homosexual men. AIDS 4, 775-781. doi: 10.1097/00002030-199008000-00009

Norman, S. E., Resnick, L., Cohn, M. A., Duara, R., Herbst, J., and Berger, J. R. (1988). Sleep disturbances in HIV-seropositive patients. JAMA 260, 922. doi: 10.1001/jama.1988.03410070046015

Obal, F. Jr., and Krueger, J. M. (2003). Biochemical regulation of non-rapid-eyemovement sleep. Front. Biosci. 8, d520-d550. doi: 10.2741/1033
Okun, M. L., Giese, S., Lin, L., Einen, M., Mignot, E., and Coussons-Read, M. E. (2004). Exploring the cytokine and endocrine involvement in narcolepsy. Brain Behav. Immun. 18, 326-332. doi: 10.1016/j.bbi.2003.11.002

Opp, M. R., Rady, P. L., Hughes, T. K. Jr., Cadet, P., Tyring, S. K., and Smith, E. M. (1996). Human immunodeficiency virus envelope glycoprotein 120 alters sleep and induces cytokine mRNA expression in rats [published errata appear in Am J Physiol 1996 Aug;271(2 Pt 2):section R following table of contents and 1996 Dec;271(6 Pt 3):section R following table of contents]. Am. J. Physiol. 270, R963-R970.

Palamaner Subash Shantha, G., Kumar, A. A., Cheskin, L. J., and Pancholy, S. B. (2015). Association between sleep-disordered breathing, obstructive sleep apnea, and cancer incidence: a systematic review and meta-analysis. Sleep Med. 16, 1289-1294. doi: 10.1016/j.sleep.2015.04.014

Partinen, M., Kornum, B. R., Plazzi, G., Jennum, P., Julkunen, I., and Vaarala, O. (2014). Narcolepsy as an autoimmune disease: the role of H1N1 infection and vaccination. Lancet Neurol. 13, 600-613. doi: 10.1016/S1474-4422(14)70075-4

Peppard, P. E., Young, T., Barnet, J. H., Palta, M., Hagen, E. W., and Hla, K. M. (2013). Increased prevalence of sleep-disordered breathing in adults. Am. J. Epidemiol. 177, 1006-1014. doi: 10.1093/aje/kws342

Pires, G. N., Bezerra, A. G., Tufik, S., and Andersen, M. L. (2016). Effects of acute sleep deprivation on state anxiety levels: a systematic review and meta-analysis. Sleep Med. 24, 109-118. doi: 10.1016/j.sleep.2016.07.019

Poroyko, V. A., Carreras, A., Khalyfa, A., Khalyfa, A. A., Leone, V., Peris, E., et al. (2016). Chronic sleep disruption alters gut microbiota, induces systemic and adipose tissue inflammation and insulin resistance in mice. Sci. Rep. 6:35405. doi: 10.1038/srep35405

Ramesh, V., Nair, D., Zhang, S. X., Hakim, F., Kaushal, N., Kayali, F., et al. (2012). Disrupted sleep without sleep curtailment induces sleepiness and cognitive dysfunction via the tumor necrosis factor-alpha pathway. J. Neuroinflammation 9:91. doi: 10.1186/1742-2094-9-91

Ravichandran, K. S. (2010). Find-me and eat-me signals in apoptotic cell clearance: progress and conundrums. J. Exp. Med. 207, 1807-1817. doi: $10.1084 /$ jem. 20101157

Renno, T., Krakowski, M., Piccirillo, C., Lin, J. Y., and Owens, T. (1995). TNFalpha expression by resident microglia and infiltrating leukocytes in the central nervous system of mice with experimental allergic encephalomyelitis. Regulation by Th1 cytokines. J. Immunol. 154, 944-953.

Rohleder, N., Aringer, M., and Boentert, M. (2012). Role of interleukin6 in stress, sleep, and fatigue. Ann. N. Y. Acad. Sci. 1261, 88-96. doi: $10.1111 / j .1749-6632.2012 .06634 . x$

Salter, M. W., and Beggs, S. (2014). Sublime microglia: expanding roles for the guardians of the CNS. Cell 158, 15-24. doi: 10.1016/j.cell.2014.06.008

Sanchez-de-la-Torre, Campos-Rodriguez, F., and Barbe, F. (2013). Obstructive sleep apnoea and cardiovascular disease. Lancet Respir. Med. 1, 61-72. doi: 10.1016/S2213-2600(12)70051-6

Sapin, E., Peyron, C., Roche, F., Gay, N., Carcenac, C., Savasta, M., et al. (2015). Chronic intermittent hypoxia induces chronic low-grade neuroinflammation in the dorsal hippocampus of mice. Sleep 38, 1537-1546. doi: $10.5665 /$ sleep. 5042

Savill, J., Dransfield, I., Gregory, C., and Haslett, C. (2002). A blast from the past: clearance of apoptotic cells regulates immune responses. Nat. Rev. Immunol. 2, 965-975. doi: 10.1038/nri957

Schafer, D. P., Lehrman, E. K., Kautzman, A. G., Koyama, R., Mardinly, A. R., Yamasaki, R., et al. (2012). Microglia sculpt postnatal neural circuits in an activity and complement-dependent manner. Neuron 74, 691-705. doi: 10.1016/j.neuron.2012.03.026

Schmidt, M. A., and Wisor, J. P. (2012). Interleukin 1 receptor contributes to methamphetamine- and sleep deprivation-induced hypersomnolence. Neurosci. Lett. 513, 209-213. doi: 10.1016/j.neulet.2012.02.040

Sekine, Y., Ouchi, Y., Sugihara, G., Takei, N., Yoshikawa, E., Nakamura, K., et al. (2008). Methamphetamine causes microglial activation in the brains of human abusers. J. Neurosci. 28, 5756-5761. doi: 10.1523/JNEUROSCI.1179-08.2008

Senaratna, C. V., Perret, J. L., Lodge, C. J., Lowe, A. J., Campbell, B. E., Matheson, M. C., et al. (2017). Prevalence of obstructive sleep apnea in the general population: a systematic review. Sleep Med. Rev. 34, 70-81. doi: 10.1016/j.smrv.2016.07.002

Shechter, A. (2016). Obstructive sleep apnea and energy balance regulation: a systematic review. Sleep Med. Rev. 34, 59-69. doi: 10.1016/j.smrv.2016.07.001 
Shemer, A., Erny, D., Jung, S., and Prinz, M. (2015). Microglia plasticity during health and disease: an immunological perspective. Trends Immunol. 36, 614-624. doi: 10.1016/j.it.2015.08.003

Siegel, J. M. (1999). Narcolepsy: a key role for hypocretins (orexins). Cell 98, 409-412. doi: 10.1016/S0092-8674(00)81969-8

Sierra, A., Abiega, O., Shahraz, A., and Neumann, H. (2013). Janus-faced microglia: beneficial and detrimental consequences of microglial phagocytosis. Front. Cell. Neurosci. 7:6. doi: 10.3389/fncel.2013.00006

Sierra, A., Tremblay, M. E., and Wake, H. (2014). Never-resting microglia: physiological roles in the healthy brain and pathological implications. Front. Cell. Neurosci. 8:240. doi: 10.3389/fncel.2014.00240

Smith, S. M., Friedle, S. A., and Watters, J. J. (2013). Chronic intermittent hypoxia exerts CNS region-specific effects on rat microglial inflammatory and TLR4 gene expression. PLoS ONE 8:e81584. doi: 10.1371/journal.pone. 0081584

Spires-Jones, T. L., and Hyman, B. T. (2014). The intersection of amyloid beta and tau at synapses in Alzheimer's disease. Neuron 82, 756-771. doi: 10.1016/j.neuron.2014.05.004

Steriade, M., Contreras, D., Curro Dossi, R., and Nunez, A. (1993a). The slow (< $1 \mathrm{~Hz}$ ) oscillation in reticular thalamic and thalamocortical neurons: scenario of sleep rhythm generation in interacting thalamic and neocortical networks. J. Neurosci. 13, 3284-3299.

Steriade, M., Nunez, A., and Amzica, F. (1993b). A novel slow ( $<1 \mathrm{~Hz}$ ) oscillation of neocortical neurons in vivo: depolarizing and hyperpolarizing components. J. Neurosci. 13, 3252-3265.

Steriade, M., Nunez, A., and Amzica, F. (1993c). Intracellular analysis of relations between the slow $(<1 \mathrm{~Hz})$ neocortical oscillation and other sleep rhythms of the electroencephalogram. J. Neurosci. 13, 3266-3283.

Stokholm, M. G., Iranzo, A., Ostergaard, K., Serradell, M., Otto, M., Svendsen, K. B., et al. (2017). Assessment of neuroinflammation in patients with idiopathic rapid-eye-movement sleep behaviour disorder: a case-control study. Lancet Neurol. doi: 10.1016/S1474-4422(17)30173-4. [Epub ahead of print].

Tabuchi, S., Tsunematsu, T., Black, S. W., Tominaga, M., Maruyama, M., Takagi, K., et al. (2014). Conditional ablation of orexin/hypocretin neurons: a new mouse model for the study of narcolepsy and orexin system function. J. Neurosci. 34, 6495-6509. doi: 10.1523/JNEUROSCI.0073-14.2014

Tafti, M. (2009). Genetic aspects of normal and disturbed sleep. Sleep Med. 10, (Suppl. 1), S17-S21. doi: 10.1016/j.sleep.2009.07.002

Tafti, M., Nishino, S., Aldrich, M. S., Liao, W., Dement, W. C., and Mignot, E. (1996). Major histocompatibility class II molecules in the CNS: increased microglial expression at the onset of narcolepsy in canine model. J. Neurosci. $16,4588-4595$

Tanaka, S., Honda, M., Toyoda, H., and Kodama, T. (2014). Increased plasma IL6, IL-8, TNF-alpha, and G-CSF in Japanese narcolepsy. Hum. Immunol. 75, 940-944. doi: 10.1016/j.humimm.2014.06.023

Tansey, M. G., McCoy, M. K., and Frank-Cannon, T. C. (2007). Neuroinflammatory mechanisms in Parkinson's disease: potential environmental triggers, pathways, and targets for early therapeutic intervention. Exp. Neurol. 208, 1-25. doi: 10.1016/j.expneurol.2007.07.004

Tartar, J. L., McKenna, J. T., Ward, C. P., McCarley, R. W., Strecker, R. E., and Brown, R. E. (2010). Sleep fragmentation reduces hippocampal CA1 pyramidal cell excitability and response to adenosine. Neurosci. Lett. 469, 1-5. doi: 10.1016/j.neulet.2009.11.032

Tay, T. L., Savage, J., Hui, C. W., Bisht, K., and Tremblay, M. E. (2016). Microglia across the lifespan: from origin to function in brain development, plasticity and cognition. J. Physiol. 595, 1929-1945. doi: 10.1113/JP272134

Thannickal, T. C., Moore, R. Y., Nienhuis, R., Ramanathan, L., Gulyani, S., Aldrich, M., et al. (2000). Reduced number of hypocretin neurons in human narcolepsy. Neuron 27, 469-474. doi: 10.1016/S0896-6273(00)00058-1

Tian, L., Hui, C. W., Bisht, K., Tan, Y., Sharma, K., Chen, S., et al. (2017). Microglia under psychosocial stressors along the aging trajectory: consequences on neuronal circuits, behavior, and brain diseases. Prog. Neuropsychopharmacol. Biol. Psychiatry 79(Pt A), 27-39. doi: 10.1016/j.pnpbp.2017.01.007

Tononi, G., and Cirelli, C. (2014). Sleep and the price of plasticity: from synaptic and cellular homeostasis to memory consolidation and integration. Neuron 81, 12-34. doi: 10.1016/j.neuron.2013.12.025

Toth, L. A., and Krueger, J. M. (1988). Alteration of sleep in rabbits by Staphylococcus aureus infection. Infect. Immun. 56, 1785-1791.
Toth, L. A., and Krueger, J. M. (1989). Effects of microbial challenge on sleep in rabbits. FASEB J. 3, 2062-2066.

Toth, L. A., Rehg, J. E., and Webster, R. G. (1995). Strain differences in sleep and other pathophysiological sequelae of influenza virus infection in naive and immunized mice. J. Neuroimmunol. 58, 89-99. doi: 10.1016/0165-5728(94)00193-R

Toth, L. A., Tolley, E. A., Broady, R., Blakely, B., and Krueger, J. M. (1994). Sleep during experimental trypanosomiasis in rabbits. Proc. Soc. Exp. Biol. Med. 205, 174-181. doi: 10.3181/00379727-205-43694

Toyoda, H., Miyagawa, T., Koike, A., Kanbayashi, T., Imanishi, A., Sagawa, Y., et al. (2015). A polymorphism in CCR1/CCR3 is associated with narcolepsy. Brain Behav. Immun. 49, 148-155. doi: 10.1016/j.bbi.2015.05.003

Tremblay, M. E., Lowery, R. L., and Majewska, A. K. (2010). Microglial interactions with synapses are modulated by visual experience. PLoS Biol. 8:e1000527. doi: 10.1371/journal.pbio.1000527

Tremblay, M. E., and Sierra, A. (2014). Microglia in Health and Disease. New York, NY:Springer.

Tremblay, M. E., Stevens, B., Sierra, A., Wake, H., Bessis, A., and Nimmerjahn, A. (2011). The role of microglia in the healthy brain. J. Neurosci. 31, 16064-16069. doi: 10.1523/JNEUROSCI.4158-11.2011

Unnikrishnan, D., Jun, J., and Polotsky, V. (2015). Inflammation in sleep apnea: an update. Rev. Endocr. Metab. Disord. 16, 25-34. doi: 10.1007/s11154-014-9304-x

Van Dam, A. M., Bauer, J., Tilders, F. J., and Berkenbosch, F. (1995). Endotoxininduced appearance of immunoreactive interleukin-1 beta in ramified microglia in rat brain: a light and electron microscopic study. Neuroscience 65, 815-826. doi: 10.1016/0306-4522(94)00549-K

Vijayan, V. K. (2012). Morbidities associated with obstructive sleep apnea. Expert Rev. Respir. Med. 6, 557-566. doi: 10.1586/ers.12.44

Vorster, A. P., and Born, J. (2015). Sleep and memory in mammals, birds and invertebrates. Neurosci. Biobehav. Rev. 50, 103-119. doi: 10.1016/j.neubiorev.2014.09.020

Wake, H., Moorhouse, A. J., Jinno, S., Kohsaka, S., and Nabekura, J. (2009). Resting microglia directly monitor the functional state of synapses in vivo and determine the fate of ischemic terminals. J. Neurosci. 29, 3974-3980. doi: 10.1523/JNEUROSCI.4363-08.2009

Wang, Y., Carreras, A., Lee, S., Hakim, F., Zhang, S. X., Nair, D., et al. (2014). Chronic sleep fragmentation promotes obesity in young adult mice. Obesity 22, 758-762. doi: 10.1002/oby.20616

Wang, Y., Zhang, S. X., and Gozal, D. (2010). Reactive oxygen species and the brain in sleep apnea. Respir. Physiol. Neurobiol. 174, 307-316. doi: 10.1016/j.resp.2010.09.001

Wisor, J. P., Schmidt, M. A., and Clegern, W. C. (2011a). Evidence for neuroinflammatory and microglial changes in the cerebral response to sleep loss. Sleep 34, 261-272. doi: 10.1093/sleep/34.3.261

Wisor, J. P., Schmidt, M. A., and Clegern, W. C. (2011b). Cerebral microglia mediate sleep/wake and neuroinflammatory effects of methamphetamine. Brain Behav. Immun. 25, 767-776. doi: 10.1016/j.bbi.2011.02.002

Wu, K. M., Lin, C. C., Chiu, C. H., and Liaw, S. F. (2010). Effect of treatment by nasal continuous positive airway pressure on serum high mobility group box-1 protein in obstructive sleep apnea. Chest 137, 303-309. doi: 10.1378/chest.09-0936

Xanthos, D. N., and Sandkuhler, J. (2014). Neurogenic neuroinflammation: inflammatory CNS reactions in response to neuronal activity. Nat. Rev. Neurosci. 15, 43-53. doi: 10.1038/nrn3617

Xie, L., Kang, H., Xu, Q., Chen, M. J., Liao, Y., Thiyagarajan, M., et al. (2013). Sleep drives metabolite clearance from the adult brain. Science 342, 373-377. doi: 10.1126/science.1241224

Xu, W., Chi, L., Row, B. W., Xu, R., Ke, Y., Xu, B., et al. (2004). Increased oxidative stress is associated with chronic intermittent hypoxia-mediated brain cortical neuronal cell apoptosis in a mouse model of sleep apnea. Neuroscience 126, 313-323. doi: 10.1016/j.neuroscience.2004.03.055

Yaffe, K., Falvey, C. M., and Hoang, T. (2014). Connections between sleep and cognition in older adults. Lancet Neurol. 13, 1017-1028. doi: 10.1016/S1474-4422(14)70172-3

Yaffe, K., Laffan, A. M., Harrison, S. L., Redline, S., Spira, A. P., Ensrud, K. E., et al. (2011). Sleep-disordered breathing, hypoxia, and risk of mild cognitive impairment and dementia in older women. JAMA 306, 613-619. doi: 10.1001/jama.2011.1115 
Yoshida, H., Peterfi, Z., Garcia-Garcia, F., Kirkpatrick, R., Yasuda, T., and Krueger, J. M. (2004). State-specific asymmetries in EEG slow wave activity induced by local application of TNFalpha. Brain Res. 1009, 129-136. doi: 10.1016/j.brainres.2004.02.055

Young, T., Palta, M., Dempsey, J., Skatrud, J., Weber, S., and Badr, S. (1993). The occurrence of sleep-disordered breathing among middle-aged adults. N. Engl. J. Med. 328, 1230-1235. doi: 10.1056/NEJM199304293 281704

Zhang, S. X., Khalyfa, A., Wang, Y., Carreras, A., Hakim, F., Neel, B. A., et al. (2014). Sleep fragmentation promotes NADPH oxidase 2-mediated adipose tissue inflammation leading to insulin resistance in mice. Int. J. Obes. 38, 619-624. doi: 10.1038/ijo.2013.139

Zhou, J., Camacho, M., Tang, X., and Kushida, C. A. (2016). A review of neurocognitive function and obstructive sleep apnea with or without daytime sleepiness. Sleep Med. 23, 99-108. doi: 10.1016/j.sleep.2016.02.008
Zielinski, M. R., Dunbrasky, D. L., Taishi, P., Souza, G., and Krueger, J. M. (2013). Vagotomy attenuates brain cytokines and sleep induced by peripherally administered tumor necrosis factor-alpha and lipopolysaccharide in mice. Sleep 36, 1227-1238. doi: 10.5665/sleep.2892

Conflict of Interest Statement: The authors declare that the research was conducted in the absence of any commercial or financial relationships that could be construed as a potential conflict of interest.

Copyright (c) 2017 Nadjar, Wigren and Tremblay. This is an open-access article distributed under the terms of the Creative Commons Attribution License (CC BY).

The use, distribution or reproduction in other forums is permitted, provided the original author(s) or licensor are credited and that the original publication in this journal is cited, in accordance with accepted academic practice. No use, distribution or reproduction is permitted which does not comply with these terms. 